\title{
Study of Functional Property of Bread Based on Buckwheat and Green Tea
}

\author{
SHRADDHA BHATTARAI ${ }^{1 *}$, PRAVIN OJHA ${ }^{1}$ and KRISHNA PRASAD RAI ${ }^{2}$
}

\author{
${ }^{1}$ National College of Food Science and Technology, Kathmandu, Nepal \\ ${ }^{2}$ Department of Food Technology and Quality Control, Babarmahal, Kathmandu
}

A study was conducted to formulate and observe the functional properties of bread based on buckwheat and green tea. The physiochemical and functional properties of the raw materials used and that of the best sample were also analyzed. The TPC in $B W F$ and GT were found to be 51 GAE and 95 GAE respectively. In other hand, antioxidant activity was found to be $7.1 \%$ and $39.2 \%$ respectively. From the sensory evaluation, the sample with 60:40 ratio of BWF: WF and 3\% GTB incorporated was found to be superior. Furthermore, iron, calcium, tannin content, total polyphenol content and antioxidant activity of the best product were found to be $3.133 \mathrm{mg} / 100 \mathrm{~g}, 315.56 \mathrm{mg} / 100 \mathrm{~g}, 0.0000084 \%, 71 \mathrm{GAE}$ and $5.6 \%$ respectively. Additionally, a comparative proximate composition analysis of the best sample and market product was analyzed and the result showed the protein content of the lab sample was about 3 times more than that of the market product. Therefore, the lab prepared bread was found to be highly nutritious with functional characteristics with acceptable sensory qualities and shelf-life.

Keywords: Green tea brew, Polyphenol, Antioxidant activity, Shelf-life

\section{Introduction}

Bread may be described as a fermented confectionary product produced mainly from wheat flour, water, yeast and salt by a series of process involving mixing, kneading, proofing, shaping and baking. Wheat is the basic ingredients of bread which is good source of calories and other nutrients but its functional properties and other nutritional qualities are lower when compared to soya bean, pea and other pseudo cereals proteins (Kent et al., 2004) The development and consumption of such functional foods not only improves the nutritional status of the general population but also helps those suffering from degenerative diseases associated with today's changing life styles and environment. Bread could be used as vehicle in the formulation of varying products with the increasing consumer demands for healthful food products. The enrichment of bread and other cereal based confections with other cereal flours has long been recognized (Dendy and Dobraszczyk, 2001).

Buckwheat is one of the most important pseudo cereals with many functional properties It contains 10 to $15 \%$ protein with a good source of all indispensable amino acids (Kent et al., 2004). It is rich in mineral content like $\mathrm{Fe}, \mathrm{Ca}, \mathrm{Zn}, \mathrm{Se}, \mathrm{Mg}$ and $\mathrm{Mn}$. It contains antioxidants like rutin and tannins. It also contains Vitamins $\mathrm{B}_{1}$ and $\mathrm{B}_{2}$ and lignans and different aromatic compounds. Different phytonutrients are responsible for its health benefits. Rutin helps in reduction of bad cholesterol and also has antioxidant properties.

Another easily available but less used food product with many health benefits is green tea. Green tea extracts can be generally divided into four aspects - antioxidant, anti carcinogen, anti-inflammatory, and anti-radiation. Green tea extracts exhibit stronger antioxidant protection for human body than Vitamin C and E. Scavenging effect of lipid freeradicals (one antioxidant property) of polyphenols in green tea extracts can be clearly observed in experiments.

\footnotetext{
*Corresponding author, E-mail: shraddhab068@yahoo.com
}

Functional properties of Buckwheat- An antioxidant can be defined as any substances that when present at low concentration compared to that of an oxidizable substrate significantly delays or inhibits the oxidation of the substrate (Atannassova, 2003). Plant polyphenols possesses antioxidant, anti-carcinogenic and anti-artioscleriotic properties (Balijeet et al., 2010).

Rutin (quercitin-3-o-rutinoside), a citrus flavonoid glycoside, and quercitin (the precursor of rutin) are the major biofunctional compounds of secondary metabolites plant belonging to the category of flavonols glycosides. It is often denoted as vitamin-P1 where as quercitin has been addressed as the main flavonols in human diet. Rutin is also known as rutoside, sophorin and quercitin-3-rutinoside. It is a flavonols glycoside comprised of the quercitin and the disaccharide rutinose (rhamnose and glucose).

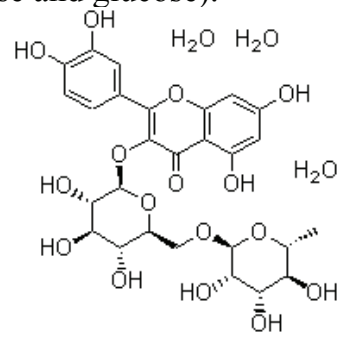

Figure 1. Chemical structure of Rutin

Antioxidant property of Rutin- Rutin as it attaches to the metallions like iron prevents it from binding to hydrogen peroxide, which would otherwise create a hydrogen reactive free radical that may damage cells. So, the best described property of rutin is its ability to act as antioxidant. Rutin seems to be most powerful flavonoids for protecting the body against reactive oxygen species, produced during the normal oxygen metabolism or are induced by exogenous damage (Kreft et al., 2005).

Anticholesterol properties of Rutin- One of the important properties of rutin is in anticholesterol property. Also it 
strengthens the capillaries and therefore can reduce the symptoms of hemophilia. LDL cholesterol and lower the risk of the heart disease. Study shows, rutin treatment on animals increase HDL- Cholesterol, and decreases the LDL one where as increased levels were found in Vitamin E (Bojnanska et al, 2009). The overall study concentration indicates that pretreatment of flavonoids was able to reduce the cardiac toxicity by reducing the lipid profiles in the rabbits. Decrease in the blood lipid profiles and increase in the HDL cholesterol in flavonoid treated groups is due to inhibition of hepatic cholesterol biosynthesis, fecal bile acid secretion and stimulation of receptor mediated catabolism of LDL cholesterol and increase in the uptake of LDL cholesterol from blood by liver (Kreft et al., 2005).

Functional properties of Green tea- The biochemical or functional properties of green tea extracts can be generally divided into four aspects - antioxidant, anti carcinogenic, antiinflammatory, and anti-radiation. Green tea extracts exhibit stronger antioxidant protection for human body than vitamin $\mathrm{C}$ and vitamin E. Scavenging effect of lipid free-radicals (one antioxidant property) of polyphenols in green tea extracts can be clearly observed in experiments. Moreover, in many experiments, green tea extracts show inhibitory effects on cancer cells. Catechin and caffeine, which are main components in green tea extracts, block the cell cycle of cancer cells (cytotoxicity) and induce programmed cell death. In addition, green tea extracts also contain a wide-ranged antiinflammatory characteristic, so it may be helpful in treating chronic inflammatory states. Therefore, green tea extracts may be effective in oral hygiene maintenance (Armoskaite et al., 2011).

\section{Materials and Methods}

Wheat flour, Buckwheat flour, Green tea were purchased from local market of Kathmandu. Green Tea of brand name 'Nepal organic Tea' and Buckwheat flour of 'mithe'were used. Reference material grade of DPPH and FC was procured from the chemical supplier of Kathmandu of Sigma Aldrich Co. and Merck Co. respectively and all other chemicals and reagents were used of analytical grade available in laboratory.

Preparations of functional bread- Altogether eight products were prepared according to the formulations shown in table 1 and 2. Product R was prepared solely from wheat flour as a reference product. Different formulations of composite flour for the preparation of bread at preliminary stage are shown in Table 1.

Table 1. Formulation of bread from composite flour at preliminary stage

\begin{tabular}{lll}
\hline Code & Wheat Flour & BW Flour \\
\hline R & 100 & 0 \\
F1 & 80 & 20 \\
F2 & 70 & 30 \\
F3 & 60 & 40 \\
F4 & 50 & 50 \\
\hline
\end{tabular}

From the sensory evaluation of the bread prepared from the above formulation, the secondary step of formulation was carried out i.e. formulation with GT brew incorporation. Different proportions of green tea in the best composition of composite flour were shown in Table 2.

Table 2. Formulation of bread with composite flour and green tea at secondary stage

\begin{tabular}{lcl}
\hline Code & Composite flour & GT Brew \\
\hline FG1 & 100 & $1 \%$ \\
FG2 & 100 & $3 \%$ \\
FG3 & 100 & $5 \%$ \\
\hline
\end{tabular}

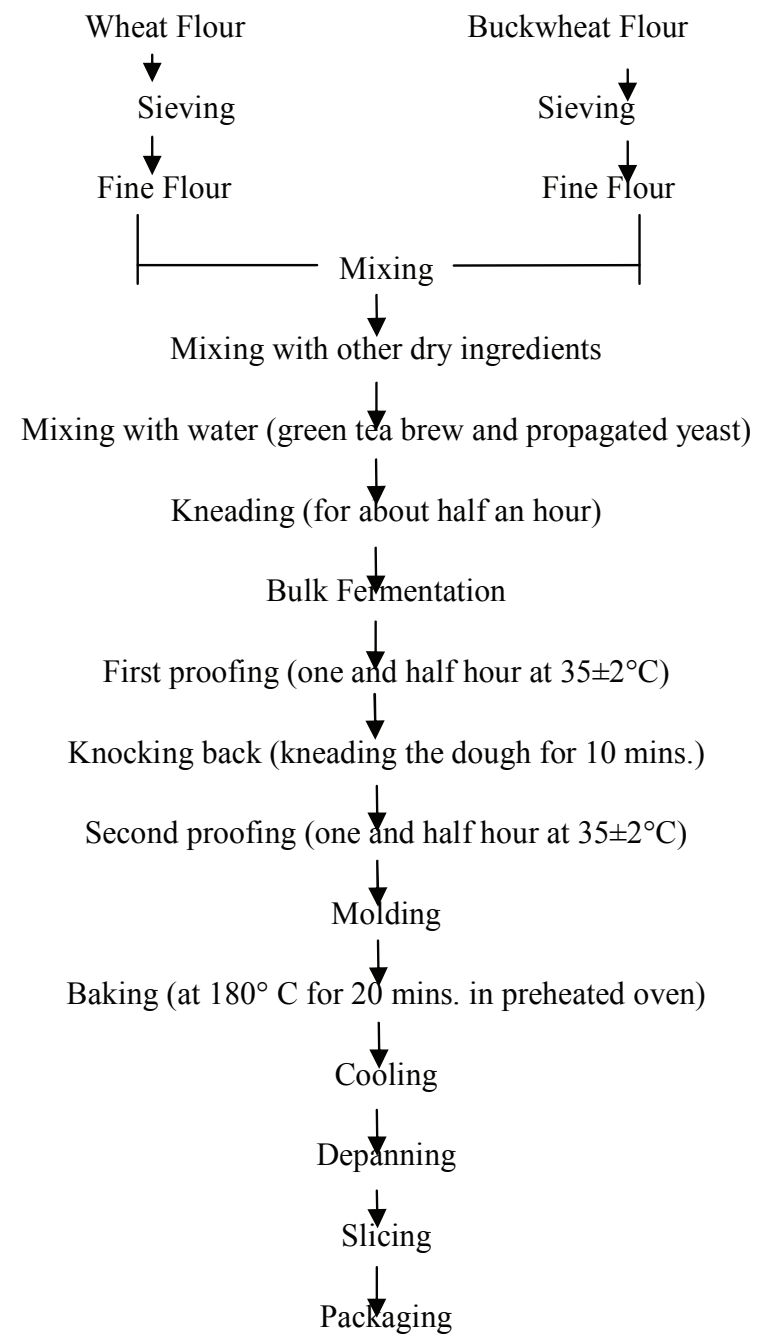

Figure 2. Flow chart of the preparation of bread with composite flour incorporating green tea brew

Chemical analysis- All raw materials and processes products were immediately analyzed in triplicate in laboratory of NCFST premises. Proximate composition, Iron content, Calcium Content, and Tannin Content, Alcoholic Acidity and 
Gluten content of the product was determined according to the method of Ranganna (2007).

\section{Determination of total polyphenol content and antioxidant} activity- Total Polyphenol Content Antioxidant activity was estimated by Folin-Ciocalteau Colorimetry as per Singleton and Rossi (1965). $1 \mathrm{ml}$ of sample was taken and to this $70 \mathrm{ml}$ of water and $5 \mathrm{ml}$ of FC was added. The solution was incubated for $1-8$ minutes at room temperature. Then, $15 \mathrm{ml}$ of sodium carbonate solution was added and the volume was made up to $100 \mathrm{ml}$ with water and again incubated to $2 \mathrm{hr}$ at room temperature. Then absorbance at $465 \mathrm{~nm}$ was taken and total polyphenol content was determined graphically calibrating with the absorbance of standard gallic acid solution.

Antioxidant activity was estimated by DPPH Colorimetry method. $250 \mathrm{mg}$ of sample was extracted with $70 \%$ methanol for $30 \mathrm{~min}$ by continuous swirling and the extract was filtered with Whatmann filter paper No.1. The volume of filtrate was made up to $25 \mathrm{ml}$. Then different concentration of sample viz. $1000 \mathrm{ug} / \mathrm{ml}, 100 \mathrm{ug} / \mathrm{ml}$ and $0.1 \mu \mathrm{g} / \mathrm{ml}$ was prepared in $70 \%$ methanol. $175 \mu \mathrm{l}$ of this respective solution and $150 \mu \mathrm{l}$ of $0.2 \mathrm{mM}$ of DPPH solution was prepared and their absorbance was taken at $0 \mathrm{~min}$ and after $30 \mathrm{~min}$ at $515 \mathrm{~nm}$.

Determination of shelf life- Shelf life was determined by observing the mold growth in stored sample by Potato Dextrose Agar (PDA) according to Manadhar, (2006).

Sensory evaluation- The bread prepared was analyzed for sensory value using scoring points as per See et al. (2007) rating system, which was carried out with respect to general appearance, crust color, crumb color, texture, taste and odour and overall acceptability. Altogether 10 semi-trained Panelists were selected for the sensory evaluation and individual panelist was provided with samples coded with 3 digit random numbers and all the samples were served simultaneously. A sheet of sensory evaluation card was provided to each panelist to score for the quality attributes. Necessary precautions were taken to prevent the carry over flavor during the tasting by ensuring that semi trained panelists rinsed their mouth with fresh water after each stage of sensory evaluation.

Statistical analysis- The result for sensory evaluation was analyzed using SPSS 16.0 (2007) for ANOVA to find out the significant difference of treatment at $95 \%$ level of confidence. The means were compared by DMRT at $95 \%$ of significance by using same software.

\section{Results and Discussion}

Sensory analysis- Sensory analysis was done according to See et al., (2007) Rating Test for each product. It was done in two phases; first for analysis of bread with composite flour only and then for bread with composite flour and GT. Sensory evaluation was based on five sensory parameters viz. Crumb Color, Crust Color, Taste and Odor Texture, and General appearance of the product. The product was then finalized for further analysis. The result of sensory analysis of both phases is given in Table 3 and 4 respectively.

Table 3. Sensory Characteristics of bread prepared from different composition of WF and BWF

\begin{tabular}{|c|c|c|c|c|c|c|}
\hline \multicolumn{2}{|c|}{ Formulation } & \multirow[b]{2}{*}{ Crust Color } & \multirow[b]{2}{*}{$\begin{array}{l}\text { Crumb } \\
\text { Color }\end{array}$} & \multirow[b]{2}{*}{$\begin{array}{l}\text { Taste } \\
\text { Odor }\end{array}$} & \multirow[b]{2}{*}{ Texture } & \multirow[b]{2}{*}{$\begin{array}{l}\text { General } \\
\text { Appearance }\end{array}$} \\
\hline WF & BWF & & & & & \\
\hline $80 \%$ & $20 \%$ & $6.5 \pm 0.97^{\mathrm{ab}}$ & $9.6 \pm 1.17^{\mathrm{a}}$ & $11.7 \pm 1.16^{\mathrm{a}}$ & $6.8 \pm 1.23^{\mathrm{a}}$ & $13.1 \pm 1.10^{\mathrm{a}}$ \\
\hline $70 \%$ & $30 \%$ & $5.9 \pm 0.99^{\mathrm{a}}$ & $9.4 \pm 1.5^{\mathrm{a}}$ & $14.1 \pm 0.38^{b}$ & $7.40 \pm 0.97^{\mathrm{ab}}$ & $15.6 \pm 2.37^{b}$ \\
\hline $60 \%$ & $40 \%$ & $7.7 \pm 0.48^{c}$ & $11.8 \pm 2.4^{\mathrm{b}}$ & $20.4 \pm 1.51^{\mathrm{c}}$ & $10.2 \pm 1.81^{\mathrm{c}}$ & $17.6 \pm 2.37^{\mathrm{c}}$ \\
\hline $50 \%$ & $50 \%$ & $6.7 \pm 1.56^{\mathrm{bc}}$ & $9.6 \pm 1.95^{\mathrm{a}}$ & $12.5 \pm 0.71^{\mathrm{a}}$ & $8.4 \pm 2.01^{\mathrm{b}}$ & $15.4 \pm 1.43^{b}$ \\
\hline
\end{tabular}

Mean $\pm S D$, Mean having different subscripts letter are significantly different $(p<0.05)$

Table 4. Sensory Characteristics of bread prepared from 60: 40 ratio of WF and BWF with different concentration of GT brew.

\begin{tabular}{cclllll}
\hline \multicolumn{2}{c}{ Formulation } & & & & \\
\cline { 1 - 2 } WF: BWF & GT & Crust Color & Crumb color & Taste & Texture & General appearance \\
\cline { 1 - 2 } $\mathbf{6 0 : 4 0}$ & $\mathbf{1 \%}$ & $7.3 \pm 1.15^{\mathrm{a}}$ & $14 \pm 3.16^{\mathrm{a}}$ & $20.2 \pm 1.31^{\mathrm{ab}}$ & $15 \pm 2.68^{\mathrm{ab}}$ & $19.4 \pm 1.6^{\mathrm{a}}$ \\
$\mathbf{6 0 : 4 0}$ & $\mathbf{3 \%}$ & $8.2 \pm 0.78^{\mathrm{b}}$ & $15 \pm 3.41^{\mathrm{a}}$ & $20.8 \pm 1.03^{\mathrm{b}}$ & $17 \pm 1.56^{\mathrm{b}}$ & $21.20 \pm 1.31^{\mathrm{b}}$ \\
$\mathbf{6 0 : 4 0}$ & $\mathbf{5 \%}$ & $6.7 \pm 0.78^{\mathrm{a}}$ & $13 \pm 2.64^{\mathrm{a}}$ & $19.1 \pm 2.28^{\mathrm{a}}$ & $14.6 \pm 2.5^{\mathrm{a}}$ & $17.6 \pm 1.429^{\mathrm{c}}$ \\
\hline
\end{tabular}

Mean \pm SD, Mean having different subscripts letter are significantly different $(\mathrm{p}<0.05)$ 


\section{Chemical and functional analysis of the final product}

Proximate composition- On the basis of all above analysis and higher value of nutrition, the final product that is bread with 60:40 ratios with $3 \%$ green tea incorporation was selected and subjected to the proximate analysis. The result is shown in graphical representation in Figure 3.

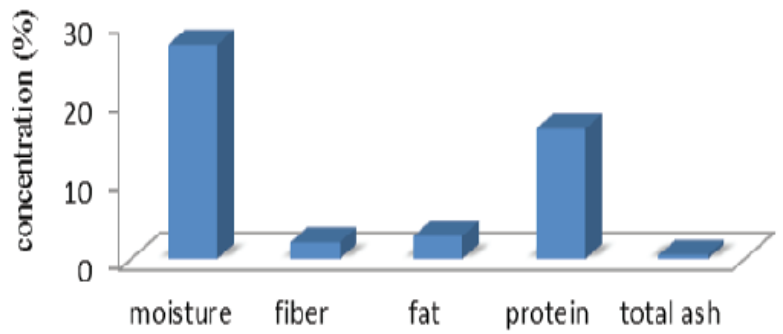

Figure 3. Proximate composition of the Final product

The moisture content of the final product was found to be $27.18 \pm 0.55 \%$. There is no such standard value of moisture content as per the HMGN 2043. But according to Kent and Amos (2004), the moisture should not be greater than 35\%. The obtained value is within the given limit. $32.6 \pm 0.5 \%$ moisture was found in rye bread prepared by See et al., (2007). It indicates that the shelf-life of bread can be extended from view point of moisture content, if packaging is proper i.e. GTR and WVTR of packaging material is as per the requirement because moisture content affects the keeping quality of the product. Crude Fat content of the product is $2.93 \pm 0.31 \%$. Similar result was seen in rye bread prepared by See et al., (2007). It contained $2.6 \pm 0.01 \%$. Fat content affects nutritional value, the satiety effect and after taste value of the product. Crude fiber as calculated is $2.12 \pm 0.16 \%$. The rye bread prepared by See et al., (2007) contained $2.36 \pm 0.03 \%$ fiber. The fiber content helps in the digestion. Crude fiber includes dietary fiber as well. Crude protein content of the product was calculated as $16.56 \pm 1.12 \%$. The protein content is significant in the product as that buckwheat flour is higher than normal flour used. The use of buckwheat flour has increased the nutritional property of the product. Total ash content of the product is $0.58 \%$ only. The ash content is affected by the bran incorporation in the flour used. If green tea itself had been used, then the ash content might have increased in the final product. But considering its appearance and aesthetic value, brew is used instead.

Micronutrient contents- The iron content, calcium content and tannin content of the product and raw materials was calculated. The result is shown in the Figure 4.

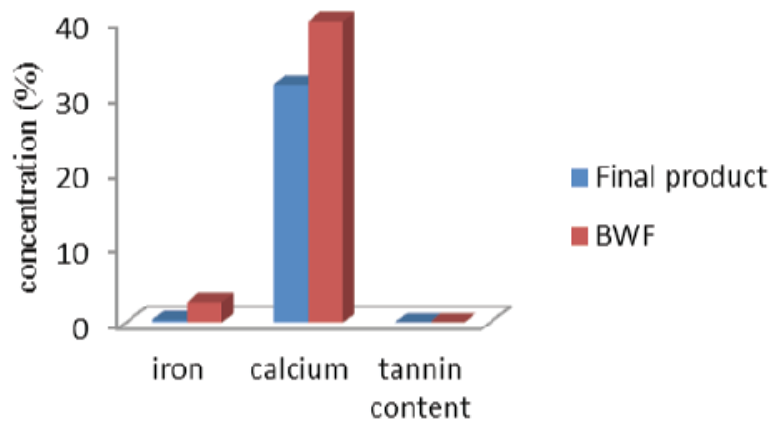

Figure 4. Micronutrients content of the final product and Buckwheat flour

Figure 4 shows the stability of the micronutrients in the baking temperature can be analyzed. As buckwheat is rich source of iron, the product is rich in iron content as well. From the study, the iron content, calcium content, Tannin content (as galtotannic acid) of the buckwheat is $2.619 \%$ was found to be $39.9 \%$ and is $0.000096 \%$ respectively and that of the product is $0.33,31.5$ and $0.0000084 \%$ respectively. The result shows that, the product is good source of minerals like calcium and iron. The stability of calcium is much more than iron in the baking temperature. Only $12 \%$ of iron was retained in the bread after baking. The low content of tannin shows that, the product is safe from its antinutritional effect on consumption. The result also can be interrelated as the stability of tannin is also less in the baking temperature. Thus, the antinutritional factors like tannin can be decreased by baking.

Analysis of functional property- The functional property (Antioxidant activity) was determined. TPC and antioxidant activity were calculated to determine its functional property. Functional property of both raw materials and product was calculated to know its retention in baking temperature. The result is shown in Figure 5 and 6.

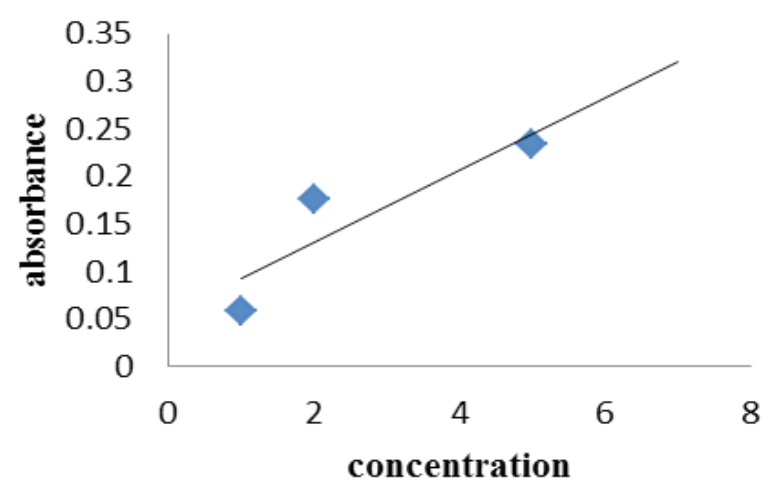

Figure 5a. Absorbance vs. Gallic acid standard 


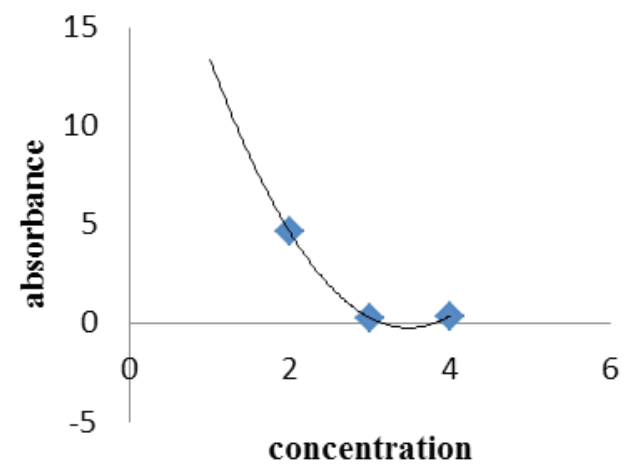

Figure 5b. Absorbance of sample

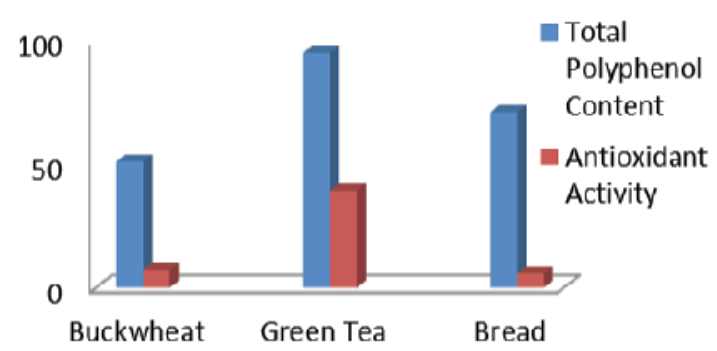

Figure 6. Functional properties of the final product and raw material

The result shows that TPC of all the samples on test was more than its Antioxidant Activity. In the study, TPC of BWF, GT and final product was found to be 51, 95 and 71 GAE respectively and Antioxidant Activity as calculated was found to be 7.1, 39.2 and 5.6 respectively. Both TPC and Antioxidant activity of GT was found to be highest and thus result showed that green tea greatly enhanced antioxidant properties of the bread. This property makes the product a functional food. The study showed that there was not much loss in the TPC of GT. Similar result was obtained in the study of Wang et al., (2004). Their result showed that the green tea catechins were relatively stable in dough during baking. There were no further detectable losses of tea catechins in bread during storage of 4 days at room temperature. It was also revealed the retention levels in freshly baked bread were 83 and $91 \%$ respectively. Also, study on buckwheat by Kreft et al., (2005), recently reported on the degradation of rutin in common buckwheat noodles, which contained approximately one-third the concentration of rutin found in flour $(0.08 \mathrm{mg} / \mathrm{g}$ vs. $0.218 \mathrm{mg} / \mathrm{g}$ respectively). Similarly, the impact of bread making and baking procedure on rutin was also evaluated, which showed that the rutin concentration continued decrease during the bread process.

Comparison of final product with normal white bread- The proximate composition of the final selected product and normal bread was compared and the result is shown in the Figure 7.

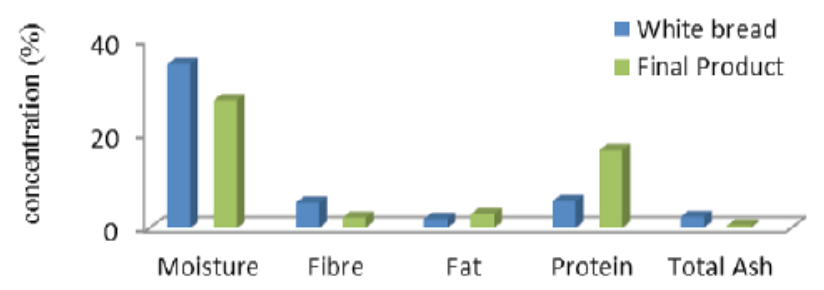

Figure 7. Comparison of proximate composition of final product and white bread

Moisture content of the normal bread was found to be $33.8 \%$ and that of product is $27.17 \%$. The texture also might get affected by the moisture content. But as from semi trained panelists, there was not much difference in the texture of the both bread. Crude fat of the white bread is $1.9 \%$ and which less than that of the product. Thus the satiety effect and after taste value of the product was more than white bread. Crude protein content is about three times more than that of normal bread i.e. only $5.6 \%$ in white bread while that of product is $15.56 \%$. From nutritional point of view, product is much richer than the white bread as it contains 3 times more protein than white bread. Total ash content of the product is less than that of normal bread. The value was found to be $2.3 \%$ for white bread and $0.58 \%$ for the product i.e. about one and half times less. As the bran content is directly proportional to the total ash content, the flour used in white bread might have more bran content. Shelf-life of the product was compared with the market bread was well, keeping both samples in room temperature. The shelf life of the product was 3 days more than that of market bread i.e. it was only 7 days for the market bread. This increment in the shelf life of the product is due to antifungal properties found in green tea. Green tea has strong and broader spectrum of antifungal activity against : fungi and antifungal activity shown by tea extracts is probably due mainly to the catechin EGCG and perhaps EGC (Wang et al., 2004).

\section{Conclusion}

Based on the study, the consumption of bread prepared with addition of buckwheat flour $40 \%$ and GTB 3\% was found to be superior from the technological point of view based on sensorial base and a baking experiment as well as from the functional point of view containing antioxidant flavonoid compounds (mainly catechins and rutin) and about three times more protein content than in market bread. It might have a positive effect to increase the serum antioxidant capacity and many other human health effects positively. The after taste value of the buckwheat gives very good impression to the consumers. The shelf life of bread was also found to be increased than normal white bread due to its antifungal properties of catechin present in GT. The anti nutritional factor present in buckwheat can be lowered in baking temperature. 
Hence, this study explored the possibility of commercialization of such functional bread based on buckwheat and green tea in future. However, further extensive works on the functional properties are still scopes of research in future.

\section{References}

Armoskaita V., Ramanauskiene K., Maruska A., Razaskes A. and Briedis V. (2011). The analysis of quality and Antioxidant activity of green tea extracts. Lithuanian University Health Sciences, 5:5:811 - 816.

Atannassova M. and Bagdassrian V. (2003). Rutin Content in Plant products. Department of Food Chemistry; National Centre of Public health Protection, 5:98:135 - 138.

Balijeet S. Y., Ritika B. Y. and Roshan L. Y. (2010). Studies on functional properties an incorporation of buckwheat flour for biscuit making. Department of Food Science and Technology, India. 1067 - 1076

Bojnanska H. Francakova P. Chlebo and A. Vollmannova (2009). Rutin content in buckwheat Enriched Bread and Influence of its consumption on Plasma Total Antioxidants Status. Faculty of Agrobiology and Food Research, Sloval Republic, 27.

Dendy Bogdan and Dobraszczyk J, (2001). Bread Making. In: Cereals and Cereal Products. Chemistry and Technology. pp. $182-232$.

Kent N. L. and Evers A. D. (2004).Technology of Bread Making. In: Kent's Technology of Cereals IV Edn, pp: $191-217$.

Kreft N. F. and K. Yasumaoto (2005). Rutin content in Buckwheat and product. Biotechnology Faculty. University of Ljubljana, Slovania, 98:508 - 512.
Manandhar S. and Sharma S. (2006). Practical Approach to Microbiology, 1iv: ${ }^{\text {st }}$ edition

Matz A. S. (2004). The Chemistry and Technology of Cereals as Food and Feed. II Edition, 26 - 57.

Noorman A. Khalaf, Shakya A. K. and Husni F. (2007). Antioxidant Activity of Some Common Plants. Faculty of Pharmacy and Medical Sciences, Jordan. 32:51 - 55.

Ranganna (2007). Handbook of Analysis and Quality Control for Fruits and Vegetables Products, New Delhi.

Wang R. and Zhou W. and Isabelle M. (2004). Stability of Tea Catechins in the Breadmaking Process; Food Science and Technology Program, Department of Chemistry, National University of Singapore, 53: $5337-5384$.

See E. F., Wan Nadiah W. A. and Noor Aziah A. A. (2007). Physico-Chemical and Sensory Evaluation of bread supplemented with Pumpkin Flour. Food Technology Division, University Sains Malaysia, 14:2P: 123 - 130.

Singleton V. L., Rossi J. A. (1965). Colorimetry of total phenolics. Am. J. Enol. Viticul., 16: 144-158.

Wang R. - Z. and W-Isabelle M. (2007). Comparison study of the effect of green tea extract (GTE) on the quality of bread by instrumental analysis and sensory evaluation. Food Res. Int., 40: 470 - 479. 